\title{
Hypervolemia-malnutrition in renal failure: Is there a relationship?
}

\author{
Ayca Inci ${ }^{1 *}$, Seyhun Kursat ${ }^{1}$, Dilek Aslan Kutsal ${ }^{1}$, Cevval Ulman² and Veysel Yavuz ${ }^{3}$ \\ *Correspondence: aycainci2004@hotmail.com \\ CrossMark \\ - Click for updates \\ ${ }^{1}$ Faculty of Medicine, Department of Nephrology, Celal Bayar University, Turkey. \\ ${ }^{2}$ Faculty of Medicine, Department of Biochemistry, Celal Bayar University, Turkey. \\ ${ }^{3}$ Faculty of Medicine, Department of Cardiology, Celal Bayar Univercity, Turkey.
}

\begin{abstract}
Background: Malnutrition is very common in chronic kidney disease patients and it starts from predialytic stage. The purpose of our project is to investigate the relationship between volume and malnutrition. Materials and method: A total of 109 chronic kidney disease patients were included in the study. Three groups have been created in patients according to their subjective global assessment (SGA) and malnutrition situation; SGA A: well feed group, SGA B: mild to moderate malnutrition, SGA C: severe malnutrition. Anthropometric measurements of all patients have been made (Body mass index, mid arm circumference, mid arm muscle circumference, triceps skinfold thickness, biceps skinfold thickness). Albumin, total chlosterol, triglyceride, serum amino acid leves have evaluated in blood samples of all patients. 24 hour ambulatory blood pressure monitoring was made for all patients.

Results: According to results average age of patients was 59.92 year and average GFR was $23.56 \mathrm{~mL} / \mathrm{min}$. 22.01 percent of patients was evaluated as SGA A and 77.98 percent of patients was evaluated as SGA B and $\mathrm{C}$. We found negative correlation between albumin, body mass index, mid arm circumference, mid arm muscle circumference, triceps skinfold thickness measurements and SGA scores. At the same time a positive correlation was found between NTSBP (Night time systolic blood pressure) and SGA scores.

Discussion: Malnutrition and hypervolemia are significant cardiovascular risk factors for chronic kidney disease patients. In this study we examine the relationship between malnutrition and hypervolemia in predialysis patients. This study was cross sectional and only ambulatory blood pressure measuring used as a volume parameter so cause and effect relationship between hypervolemia-malnutrition should not be inferred. This study should be taken into consideration because it's the first study that examines the relationship between ambulatory blood pressure and malnutrition in prediyalisis patients. Also our data shows statistically significant relationship between amino acid levels and blood pressure parameters and this study is the first reported data in this topic.
\end{abstract}

Keywords: Malnutrition, hypervolemia, subjective global assesment, renal failure

\section{Introduction}

Malnutrition is very common in chronic kidney disease (CKD). Malnutrition was detected in $23-76 \%$ of hemodialysis patients and $18-50 \%$ of peritoneal dialysis patients in previous studies. This wide range of malnutrition prevalence may be related with age, comorbidities and effectiveness of dialysis treatment $[1,2]$. Determination of nutritional status is of great importance in chronic kidney disease patients because there is a close relationship between nutritional status and clinical outcomes.
For this purpose, methods like biochemical tests (albumin, prealbumin, transferrin, serum aminoacids), anthropometric measurements and bioelectrical impedance, dual emission $x$-ray absorptiometry, nuclear magnetic resonance are used. Subjective Global Assessment (SGA) is a clinical scoring system proposed for assessment of uremi c malnutrition by several nephrology societies. This scoring system is a completely clinical assay including weight changes, food intake, gastrointestinal symptoms and functional capacity of the individual [3-8]. 
Inci et al. Clinical Nephrology and Urology Science 2015,

http://www.hoajonline.com/journals/pdf/2054-7161-2-1.pdf

doi: 10.7243/2054-7161-2-1

Cardiovascular diseases is the main cause of death in chronic kidney disease and hypertension is a significant risk factor for cardiovascular events [9]. Although pathogenesis of hypertension is multifactorial in CKD patients, increased extracellular volume and sodium intake are the most important two risk factors. Aggressive control of extracellular volume and dietary sodium intake may normalize blood pressure in CKD patients [10]. Normal diurnal-circadian rhythm is impaired in many renal failure patients. Coexistency with nocturnal hypertension is seen in these patients. Patients whose diurnal blood pressure is normal and nocturnal blood pressure does not decrease as expected are still under the risk of hypertension-related cardiovascular morbidity [11]. In a prospective study evaluating the influence of ambulatory blood pressure parameters on prognosis and mortality, diurnal blood pressure fluctuations detected with ambulatory blood pressure measurements were seen to have a prognostic value in hemodialysis patients. More than usual end organ injury develops in these patients [12].

Although it is well known that malnutrition increases cardiovascular mortality and morbidity in predialytic patients with CKD, its relationship with ambulatory blood pressure parameters has not been previously evalauted in predialytic patients. In this study we examine the relationship between malnutrition and arterial blood pressure variations. This manuscript is an extended version of a conference paper presented at the. The XI'th Congress of the Balkan Cities Association of Nephrology, Dialysis, Transplantation and Artificial Organs (BANTAO, 2013).

\section{Materials and methods}

One hundred and twenty two patients with low clearance CKD who were followed up by the Nephrology Department of Celal Bayar University between 01.01.2009 and 15.07.201, who did not receive dialysis and had hyptertension were included in the study. Patients who had acute renal failure, chronic liver diseases, chronic obstructive pulmonary diseases, malignities, myocardial infarction, congestive heart failure, chronic gastrointestinal diseases were not included in the study. Thirteen patients were excluded from the study due to technical incompatibility during tests. The research protocol was approved by the Medical Ethics Committee of Celal Bayar University, and all subjects included in the present study provided their informed consent.

Consequently, a total of 109 patients ( 67 male, 42 female) with mean age of 59.93 years completed the study. Primary renal diseases of the cases were as follows; diabetic nephropathy $(n=41,37.6 \%)$, hypertensive nephrosclerosis $(n=46$, $42.2 \%$ ), adult autosomal dominant polycystic kidney disease $(n=7,6.4 \%)$, chronic glomerulonephritis $(n=6,5.5 \%)$, cases with undetectable causes $(n=9,8.25 \%)$. Results of these cases were analysed. Presence of diabethic nephropathy, hypertensive nephrosclerosis and angiotensin converting enzyme inhibitors, angiotensin reseptor blocker, calcium channel blocker, diuretic use ratios were similar in SGA groups.

Ambulatory blood pressure monitorization (ABPM) was performed using an ambulatory blood pressure monitor (Cardio Navigator, Tracker 2 NIBP, Raynaulds Medical Ltd, Hertford, England UK) in all patients. Diurnal blood pressure measurements (between 08:00-20:00) were done every 20 min and nocturnal blood pressure measurements (between 20:00-08:00) were done every $30 \mathrm{~min}$. Physical activity of the patients was not restricted during monitorization and they were allowed to maintain their daily activities. Mean diurnal and nocturnal systolic-diastolic blood pressures and mean 24-hour systolic-diastolic blood pressures of all cases were calculted after ABPM. Patients whose mean nocturnal/diurnal blood pressure was $0.8-0.9$ were classified as dipper and the ones whose mean values were above 0.9 were classified as non-dipper. Medictaions that were used during the study (diuretics, calcium channel antagonists, angiotensin-converting enzyme inhibitors, angiotensin receptor blockers etc) were not changed.

Blood pressure values obtianed with ABPM were categorized as follows: 24-hour systolic blood pressure (24- h SBP), 24-hour diastolic blood pressure (24-h DBP), 24-hour mean arterial pressure (24-h MAP), 24-hour pulse pressure (24-h PP), diurnal systolic blood pressure (DT SBP), diurnal distolic blood pressure (DT DB), diurnal mean arterial pressure (DT MAP), diurnal pulse pressure (DT PP), nocturnal systolic blood pressure (NT SBP), nocturnal diastolic blood pressure (NT DBP), nocturnal mean arterial pressure (NT MAP), nocturnal pulse pressure (NT PP).

Fasting serum samples were obtained within the periods that 24-hour ambulatory blood pressure meaurement was done, centrifuged and stored at $80^{\circ} \mathrm{C}$ for a period not exceeding six months. All samples were examined at Celal Bayar University Biochemistry Laboratory.

Clinical assessment of nutritional status was done with SGA based on anemnesis and physical examination. Patients were evaluated for the change in body weight within the pass 6 months ( $<5 \%, 5-10 \%$ or $>10 \%$ loss), change in food intake, gastrointestinal symptoms (loss of apetite, nausea, vomiting, diarrhea) functional capacity. Each property was scored as SGA-A (normal nutrition), SGA-B (mild-moderate malnutrition) or SGA-C (severe malnutrition). On physical examination, triceps skin-fold thickness (TSF), loss of muscle mass (in deltoid and quadriceps region) and presence of edema (ankle, sacral region or acid) were evaluated. Each parameter evaluated on physical examination was scored as $0=$ normal, $S G A>21$, $2+=$ moderate, $3+=$ severe. Mid-arm circumference (MAC) was measured and recorded. Triceps skin- fold (TSF) thickness and biceps skin-fold (BSF) thickness were measured using Harpender ruler. Mid-arm muscle circumference which is a derived value based on these parameters was calculated using the formula [MAMC $=$ MAC $-(3.1415 x T S F)]$.

Data obtained in the study were entered into the database formed in the SPSS (Statistical Package For Social Sciences) 15.0 program, statistical analysis of data was done using the 
same program. Frequency tables of class variables were formed. Mean, standard deviation, median, minimum and maximum values of continuous variables and subgroups were found. Consistency to normal distribution was investigated for all continuous variables and subgroups considering both graphical research and normality tests and sample size. Variance analysis was done by constituting ANOVA tables in multiple group comparisons. Kruskal-Wallis test, one of the non-parametric methods was applied in variables that are abnormally distributed. Post-hoc tests were used in order to detect the differences between groups showing significant difference. Cross-tabs of class variables were constituted and equality of inter-group difference was analysed with qui-square tests. Correlation analysis was done in order to determine the relationship between variables. Regression analysis was done in order to investigate the linear correlations of variables related with SGA. Type one error ratio (alpha) was selected as 0.05 in all tests and two-way test was done. A p level of $<0.05$ was accepted as statistically significant.

\section{Results}

One hundred and nine patients included in the study were divided to three groups according to SGA scores. Patients whose SGA score was beteen 7-11 were determined as well nourished patients (SGA A), SGA between 12-20 as moderately nourished (SGA B) and SGA $>21$ as Malnurished (SGA C). Distribution and dermographic/anthropometric data of the patients in these 3 groups are shown in Table 1.

Table 1. Dermographic and anthropometric data of cases according to SGA scores.

\begin{tabular}{lllll}
\hline & $\begin{array}{l}\text { SGA A } \\
(\mathbf{n}: 24)\end{array}$ & $\begin{array}{l}\text { SGA B } \\
(\mathbf{n}: 58)\end{array}$ & $\begin{array}{l}\text { SGA C } \\
(\mathbf{n}: 27)\end{array}$ & p \\
\hline $\begin{array}{l}\text { Gender } \\
\text { M/F }\end{array}$ & $14 / 10$ & $34 / 24$ & $19 / 8$ & 0.548 \\
Age & $56.46 \pm 13.11$ & $60.09 \pm 11.71$ & $62.67 \pm 15.40$ & 0.238 \\
BMI & $26.88 \pm 5.85$ & $26.26 \pm 5.52$ & $21.26 \pm 2.74$ & $0.000^{*}$ \\
TSF & $11.63 \pm 2.12$ & $10.90 \pm 1.81$ & $9.70 \pm 2.03$ & $0.002^{*}$ \\
BSF & $4.79 \pm 1.31$ & $4.38 \pm 0.93$ & $3.70 \pm 0.77$ & $0.001^{*}$ \\
MAC & $28.04 \pm 3.66$ & $27.71 \pm 4.05$ & $23.93 \pm 2.25$ & $0.000^{*}$ \\
MAMC & $24.37 \pm 3.28$ & $24.32 \pm 3.89$ & $20.94 \pm 2.23$ & $0.000^{*}$ \\
MDRD & $27.25 \pm 11.73$ & $22.07 \pm 9.69$ & $23.52 \pm 10.23$ & 0.122 \\
\hline
\end{tabular}

"p<0.05 TSF: Triceps skin-fold thickness; BSF: Biceps skin-fold thickness; MAC: Mid-arm circumference; MAMC: Mid-arm mucle area circumference

No difference was detected between groups in terms of age, gender distribution and glomerular filtration rates calculated according to MDRD. BMI, TSF, BSF, MAC, MAMC were significantly different between groups $(p<0.005)$. Serum albumin values were below normal in all 3 groups and albumin level was found to reduce as SGA value increased $(p<0.001)$ (Table 2).

Correlation between blood pressure measurements, anthropometric measurements and biochemical values of the patients tested. A significant negative correlation was detected between 24HSBP, DTSBP and NTSBP and albumin, essential aminoacid, non-essenial aminoacid and BCAA (branched-chain amino acids) values (Table 3).

A significant difference was detected between NTSBP measurements according to SGA scores (p:0.021) (Table 4). In post-hoc test, significant difference was found between SGA-A and SGA-C (p:0.016) and there was no significant difference between SGA-A and SGA-B, SGA-B and SGA-C. In the SGA-A group, $9(37.5 \%)$ were dippers and 15 (62.5\%) were non-dippers. In the SGA-B group, 14 (24.1\%) were dippers and 44 (75.9\%) were non-dippers. In the SGA-C group, 4 (14.8\%) were dippers and 23 (85.2\%) were non-dippers. These differences were not statistically significant (p:0.171).

We detected a significant difference among the groups in terms of NTSBP/DTSBP (Table 5). Mann-Whitney $U$ test showed that there were no significant differences between SGA-A and SGA-B and SGA-B and SGA-C. However, differences between SGA-A and SGA-C groups were statistically significant (p:0.024). Analyses, in which we explored the relationship of night/ day time blood pressure ratio with malnutrition parameters, showed that BMI, MAC, MAMC measurements, albumin hemoglobin, cholesterol and triglyceride levels were inversely correlated, and these correlations were not statistically significant (Table 6). Multiple regression analyses to detect the predictors of SGA score indicated a strong and inverse association of the SGA scores with albumin levels (Table 7).

\section{Discussion}

Regular monitoring of nutritional status in patients with CKD is critical in pre-dialysis. Progress and the possible complications of malnutrition can be prevented if it is diagnosed and treated early. In our study, we first evaluated malnutrition using SGA. It is an important clinical scoring system for nephrologists to evaluate uremic malnutrition $[3,4]$. Studies indicate that $23-76 \%$ of hemodialysis patients and $18-50 \%$ of peritoneal dialysis patients experience malnutrition. Large differences in prevalence might be related to age, comorbid diseases and the effectiveness of dialysis treatment $[\mathbf{1 , 2}]$. Our patients were classified in 3 groups based on their SGA scores as follows: SGA-A (well-fed) (22.01\%) and SGA-B and C (moderate and severe malnutrition) (77.98\%). We believe that, in our study population, malnutrition scores were high because the majority of them were in the later stages of CRF.

We found significant associations between SGA scores and anthropometric measures (Table 1). As malnutrition level increased, MAC, MAMC, TSF, BSF and BMI levels significantly decreased. In a study by Marckman et al., a negative correlation was shown between MAMC measurements and mortality [1]. We detected negative correlations between MAC, MAMC, TSF measurements and mean 24HSBP, DTSBP and NTSBP, although 
Inci et al. Clinical Nephrology and Urology Science 2015,

http://www.hoajonline.com/journals/pdf/2054-7161-2-1.pdf

Table 2. Biochemical values of the cases according to SGA scores.

\begin{tabular}{lllll}
\hline & SGA A (n:24) & SGA B (n:58) & SGA C (n:27) & p \\
\hline Albumin & $3.76 \pm 0.36$ & $3.45 \pm 0.40$ & $3.20 \pm 0.43$ & $0.001^{*}$ \\
Hemoglobin & $12.14 \pm 1.80$ & $11.46 \pm 1.54$ & $11.57 \pm 1.19$ & 0.185 \\
Urea & $86.54 \pm 48.60$ & $108.97 \pm 43.24$ & $97.52 \pm 46.30$ & 0.115 \\
Creatinine & $2.65 \pm 1.15$ & $3.16 \pm 1.42$ & $3.00 \pm 1.27$ & 0.303 \\
Calcium & $9.31 \pm 0.61$ & $9.31 \pm 0.81$ & $9.38 \pm 0.70$ & 0.919 \\
Phosphorous & $4.44 \pm 1.24$ & $4.53 \pm 1.02$ & $4.79 \pm 1.19$ & 0.485 \\
Potassium & $4.67 \pm 0.58$ & $4.59 \pm 0.70$ & $4.82 \pm 0.78$ & 0.380 \\
Cholesterol & $180.79 \pm 45.22$ & $184.66 \pm 51.75$ & $180.44 \pm 37.61$ & 0.905 \\
Triglyceride & $137(36-225)$ & $148.50(53-524)$ & $103(30-236)$ & $0.001^{*}$ \\
\hline${ }^{*} \mathrm{p}<0.05$. & & & &
\end{tabular}

Table 3. Correlation between anthropometric measurements and biochemical values of the cases and blood pressure measurements.

\begin{tabular}{|c|c|c|c|c|c|c|}
\hline & 24HSBP & 24HDBP & DTSBP & DTDBP & NTSBP & NTDBP \\
\hline \multirow[t]{2}{*}{ BMI } & $\mathrm{r}:-0.002$ & $\mathrm{r}: 0.121$ & $\mathrm{r}: 0.035$ & $\mathrm{r}: 0.156$ & r:-0.095 & $\mathrm{r}: 0.048$ \\
\hline & p:0.984 & $\mathrm{p}: 0.211$ & p:0.718 & $\mathrm{p}: 0.104$ & $\mathrm{p}: 0.324$ & p:0.623 \\
\hline \multirow[t]{2}{*}{ TSF } & $\mathrm{r}:-0.042$ & $\mathrm{r}: 0.051$ & r:-0.046 & $\mathrm{r}: 0.077$ & $\mathrm{r}:-0.027$ & $\mathrm{r}: 0.013$ \\
\hline & $\mathrm{p}: 0.664$ & $\mathrm{p}: 0,598$ & $\mathrm{p}: 0.635$ & p:0.425 & $\mathrm{p}: 0.780$ & $\mathrm{p}: 0.894$ \\
\hline \multirow[t]{2}{*}{ MAC } & r:- -0.032 & $\mathrm{r}: 0.057$ & $\mathrm{r}: 0.057$ & $\mathrm{r}: 0.093$ & r:-0.099 & $\mathrm{r}: 0.001$ \\
\hline & $\mathrm{p}: 0.741$ & $\mathrm{p}: 0.553$ & $\mathrm{p}: 0.951$ & $\mathrm{p}: 0.337$ & $\mathrm{p}: 0.304$ & $\mathrm{p}: 0.991$ \\
\hline \multirow[t]{2}{*}{ MAMC } & $\mathrm{r}:-0.036$ & $\mathrm{r}: 0.070$ & $\mathrm{r}:-0.005$ & $\mathrm{r}: 0,103$ & r:-0.109 & $\mathrm{r}: 0.017$ \\
\hline & $\mathrm{p}: 0.711$ & p:0.469 & p:0.963 & $\mathrm{p}: 0.285$ & $\mathrm{p}: 0.260$ & $\mathrm{p}: 0.859$ \\
\hline \multirow[t]{2}{*}{ Albumin } & $\underline{\mathrm{r}:-0.233^{*}}$ & r:-0.074 & $\underline{\mathrm{r}:-0.217^{*}}$ & $\mathrm{r}:-0.064$ & $\underline{\mathrm{r}:-0.269^{*}}$ & r:-0.101 \\
\hline & p:0.015 & $\mathrm{p}: 0.442$ & $\underline{\mathrm{p}: 0.024^{*}}$ & $\mathrm{p}: 0.509$ & p:0.005 & $\mathrm{p}: 0.297$ \\
\hline \multirow[t]{2}{*}{ Hemoglobin } & $\mathrm{r}:-0.134$ & $\mathrm{r}: 0.000$ & r:-0.100 & $\mathrm{r}: 0.025$ & r:-0.021 & r:-0.047 \\
\hline & $\mathrm{p}: 0.165$ & $\mathrm{p}: 1.000$ & $\mathrm{p}: 0.302$ & $\mathrm{p}: 0.799$ & $\mathrm{p}: 0.831$ & $\mathrm{p}: 0.626$ \\
\hline \multirow[t]{2}{*}{ Triglyceride } & $\mathrm{r}: 0.020$ & $\mathrm{r}: 0.047$ & $\mathrm{r}: 0.058$ & $\mathrm{r}: 0.073$ & $\mathrm{r}:-0.023$ & $\mathrm{r}: 0.002$ \\
\hline & $\mathrm{p}: 0.835$ & $\mathrm{p}: 0.624$ & $\mathrm{p}: 0.551$ & $\mathrm{p}: 0.450$ & p:0.809 & $\mathrm{p}: 0.984$ \\
\hline \multirow[t]{2}{*}{ Cholesterol } & r: 0.071 & $\underline{\mathrm{r}: 0.221^{*}}$ & r:0.089 & $\underline{\mathrm{r}: 0.214^{*}}$ & $\mathrm{r}: 0.021$ & r:0.154 \\
\hline & $\mathrm{p}: 0.466$ & p:0.021 & $\mathrm{p}: 0.359$ & $\mathrm{p}: 0.025^{*}$ & $\mathrm{p}: 0.827$ & $\mathrm{p}: 0.110$ \\
\hline \multirow[t]{2}{*}{ Essential aminoacid } & $\underline{\mathrm{r}:-0.334}$ & $\mathrm{r}:-0.162$ & $\underline{\text { r:-0.299 }}$ & $\mathrm{r}:-0.146$ & $\underline{\text { r:- }-0.338}$ & r:-0.197 \\
\hline & p:0.000 & p:0.092 & p:0.002 & p:0.129 & $\mathrm{p}: 0.000$ & p:0.040 \\
\hline \multirow[t]{2}{*}{ Non-essential aminoacid } & $\underline{\mathrm{r}:-0.260}$ & r:-0.083 & $\underline{\mathrm{r}:-0.214}$ & $\mathrm{r}:-0.054$ & $\underline{\mathrm{r}:-0.311}$ & r:-0.193 \\
\hline & $\mathrm{p}: 0.006$ & $\mathrm{p}: 0.393$ & $\mathrm{p}: 0.025$ & $\mathrm{p}: 0.578$ & p:0.001 & $\mathrm{p}: 0.045$ \\
\hline \multirow[t]{2}{*}{ BCCA } & $\underline{r:-0.305}$ & $\mathrm{r}:-0.154$ & $\underline{\mathrm{r}:-0.282}$ & $\mathrm{r}:-0.149$ & $\underline{r:-0.299}$ & $\mathrm{r}:-0.169$ \\
\hline & p:0.001 & $\mathrm{p}: 0.110$ & p:0.003 & $\mathrm{p}: 0.122$ & p:0.002 & p:0.078 \\
\hline
\end{tabular}

$\mathrm{p}<0.05^{*}$.

these were not statistically significant (Table 3).

Hypervolemia and malnutrition are considered non-traditional risk factors for CKD and cardiovascular diseases. There are several factors that cause malnutrition in CKD. In the current study, we used the ABP measurement as a volume parameter and we aimed to evaluate the relationship between nighttime blood pressure, night/day time blood pressure ratio and malnutrition.

Serum albumin levels are the most commonly used biochemical parameter to evaluate malnutrition. In accordance 
Inci et al. Clinical Nephrology and Urology Science 2015, http://www.hoajonline.com/journals/pdf/2054-7161-2-1.pdf

Table 4. Blood pressure according to SGA score.

\begin{tabular}{lllll}
\hline & SGA -A (n:24) & SGA-B (n:58) & SGA-C (n:27) & p \\
\hline 24HSBP & $129.38 \pm 14.05$ & $136.66 \pm 14.96$ & $139.56 \pm 20.56$ & 0.075 \\
24HDBP & $73.67 \pm 11.02$ & $77.88 \pm 13.22$ & $77.93 \pm 13.03$ & 0.360 \\
$24 \mathrm{HMAP}$ & $92.25 \pm 10.79$ & $97.05 \pm 12.25$ & $98.41 \pm 14.53$ & 0.182 \\
$24 \mathrm{HPP}$ & $55.67 \pm 11.53$ & $59.02 \pm 13.19$ & $61.70 \pm 14.01$ & 0.261 \\
DTSBP & $131.13 \pm 13.73$ & $138.66 \pm 15.38$ & $139.96 \pm 20.57$ & 0.112 \\
DTDBP & $74.96 \pm 11.39$ & $79.60 \pm 14.18$ & $78.30 \pm 13.34$ & 0.365 \\
DTMAP & $93.71 \pm 11.01$ & $98.86 \pm 13.15$ & $98.93 \pm 14.76$ & 0.239 \\
DTPP & $56.17 \pm 11.24$ & $58.98 \pm 13.64$ & $62.70 \pm 14.44$ & 0.217 \\
NTSBP & $\underline{\mathbf{1 2 4 . 0 8} \pm \mathbf{1 6 . 1 8}}$ & $\underline{\mathbf{1 3 1 . 9 7} \pm \mathbf{1 7 . 3 2}}$ & $\underline{\mathbf{1 3 8 . 7 4} \pm \mathbf{2 2 . 1 6}}$ & $\mathbf{0 . 0 2 1}$ \\
NTDBP & $70.54 \pm 11.65$ & $74.22 \pm 12.93$ & $76.74 \pm 13.43$ & 0.226 \\
NTMAP & $88.63 \pm 11.77$ & $93.40 \pm 12.96$ & $97.41 \pm 15.30$ & 0.068 \\
NTPP & $54.46 \pm 12.30$ & $58.05 \pm 14.13$ & $61.96 \pm 15.31$ & 0.167 \\
Dipper/Nondipper & $9 / 15$ & $14 / 44$ & $27 / 82$ & 0.171 \\
\hline
\end{tabular}

Table 5. Comparison of nocturnal/diurnal blood pressure ratios with SGA score.

\begin{tabular}{lllll}
\hline & SGA-A & SGA-B & SGA-C & p \\
\hline NTSBP/DTSBP & $0.94 \pm 0.06$ & $0.95 \pm 0.08$ & $0.99 \pm 0.07$ & $0.053^{*}$ \\
NTDBP/DTDBP & $0.94 \pm 0.09$ & $0.93 \pm 0.09$ & $0.98 \pm 0.07$ & 0.091 \\
NTMAP/DTMAP & $0.94 \pm 0.07$ & $0.94 \pm 0.08$ & $0.98 \pm 0.07$ & 0.114 \\
NTPP/DTPP & $0.96 \pm 0.06$ & $0.98 \pm 0.09$ & $0.99 \pm 0.10$ & 0.579 \\
\hline
\end{tabular}

$\mathrm{p}<0.05^{*}$.

with previous publications, we found a negative and significant correlation between serum albumin level and malnutrition. When albumin, BMI, TSF, MAC, MAMC and NTSBP were used in the same model, albumin was inversely associated with SGA scores in multivariate regression analysis (Table 7). There are several factors affecting the synthesis, distribution and catabolism of albumin, such as inhibition of synthesis, loss of albumin, degradation, dilution as a result of fluid excess and alterations between intracellular and extracellular areas [13]. In our study, we detected negative and significant correlations between albumin levels and mean 24HSBP, DTSBP, NTSBP and NTMAP levels (Table 3 ).

There were no significant differences among groups in terms of essential and non-essential amino acids. In accordance with previous publications, BCCA levels (valine, leucine, isoleucine) decreased with increased SGA scores. The sum of the essential amino acids, the sum of the non-essential amino acids and the sum of the BCCA levels were inversely correlated with mean 24HSBP, DTSBP and NTSBP values (Table 3). Serum levels of amino acids do not reflect the total amount of amino acids in the body. The majority of amino acids exist in the intracellular compartment of skeletal muscles [14]. Studies showed that
Table 6. Relationship between nocturnal/diurnal blood pressure ratios and malnutrition parameters.

\begin{tabular}{lllll}
\hline & NTSBP/ & NTDBP/ & NTMAP/ & NTPP/ \\
& DTSBP & DTDBP & DTMAP & DTPP \\
\hline BMI & $\mathrm{r}:-0.172$ & $\mathrm{r}:-0.153$ & $\mathrm{r}:-0,158$ & $\mathrm{r}:-0.090$ \\
& $\mathrm{p}: 0.075$ & $\mathrm{p}: 0.112$ & $\mathrm{p}: 0.102$ & $\mathrm{p}: 0.353$ \\
MAC & $\mathrm{r}:-0.087$ & $\mathrm{r}:-0.099$ & $\mathrm{r}:-0.093$ & $\mathrm{r}: 0.008$ \\
& $\mathrm{p}: 0.368$ & $\mathrm{p}: 0.307$ & $\mathrm{p}: 0.335$ & $\mathrm{p}: 0.936$ \\
MAMC & $\mathrm{r}:-0.110$ & $\mathrm{r}:-0.118$ & $\mathrm{r}:-0.112$ & $\mathrm{r}:-0.010$ \\
& $\mathrm{p}: 0.253$ & $\mathrm{p}: 0.223$ & $\mathrm{p}: 0.246$ & $\mathrm{p}: 0.916$ \\
TSF & $\mathrm{r}: 0.056$ & $\mathrm{r}: 0.015$ & $\mathrm{r}: 0.018$ & $\mathrm{r}: 0.095$ \\
& $\mathrm{p}: 0.566$ & $\mathrm{p}: 0.878$ & $\mathrm{p}: 0.855$ & $\mathrm{p}: 0.327$ \\
Albumin & $\mathrm{r}:-0.124$ & $\mathrm{r}:-0.021$ & $\mathrm{r}:-0.062$ & $\mathrm{r}:-0.156$ \\
& $\mathrm{p}: 0.199$ & $\mathrm{p}: 0.830$ & $\mathrm{p}: 0.522$ & $\mathrm{p}: 0.106$ \\
Cholesterol & $\mathrm{r}:-0.088$ & $\mathrm{r}:-0.107$ & $\mathrm{r}:-0.112$ & $\mathrm{r}:-0.030$ \\
& $\mathrm{p}: 0.361$ & $\mathrm{p}: 0.266$ & $\mathrm{p}: 0.247$ & $\mathrm{p}: 0.755$ \\
Triglyceride & $\mathrm{r}:-0.109$ & $\mathrm{r}:-0.108$ & $\mathrm{r}:-0.113$ & $\mathrm{r}:-0.093$ \\
& $\mathrm{p}: 0.257$ & $\mathrm{p}: 0.265$ & $\mathrm{p}: 0.241$ & $\mathrm{p}: 0.335$ \\
Hemoglobin & $\mathrm{r}:-0.142$ & $\mathrm{r}:-0.132$ & $\mathrm{r}:-0.170$ & $\mathrm{r}:-0.129$ \\
& $\mathrm{p}: 0.142$ & $\mathrm{p}: 0.171$ & $\mathrm{p}: 0.078$ & $\mathrm{p}: 0.181$ \\
\hline
\end{tabular}

$\mathrm{p}<0.05^{*}$.

serum amino acid levels are not correlated with intracellular concentrations in skeletal muscles in patients with CKD [15]. In light of the information obtained from previous studies, it was indicated that amino acid levels are not very effective to evaluate malnutrition, as they do not completely indicate malnutrition, and detecting amino acid levels is costly and time consuming. 
Inci et al. Clinical Nephrology and Urology Science 2015,

http://www.hoajonline.com/journals/pdf/2054-7161-2-1.pdf

Table 7. Multiple regression analysis of factors affecting SGA score.

\begin{tabular}{lll}
\hline & $\mathbf{r}$ & $\mathbf{p}$ \\
\hline Albumin & $\mathbf{- 0 . 3 5 8 ^ { * }}$ & $\mathbf{0 . 0 0 0}$ \\
BMI & -0.163 & 0.234 \\
MAC & -0.771 & 0.264 \\
MAMC & 0.717 & 0.252 \\
TSF & 0.151 & 0.294 \\
NTSBP & 0.142 & 0.093 \\
\hline${ }^{*}<0.05$. & &
\end{tabular}

Hypertension exists in approximately $80-85 \%$ of CKD patients, and as GFR decreases, the prevalence of HT increases [16]. We used a 24-hour holter monitor to measure blood pressure in our study. It was shown that ambulatory measurements predict chronic renal failure, cardiovascular diseases and mortality better than office blood pressure $[17,18]$. Blood pressure decreases at night $10-20 \%$ compared to daytime levels. This expected decrease is called dipper and a decrease less than $10 \%$ is called non-dipping. Non-dipping is a risk factor for microalbuminuria, increased protein expression and decreased creatinine clearance [19-21]. CKD is a risk factor of increased blood pressure at night $[22,23]$. Bankır et al., showed the association between non-dipper and a decrease in urinal sodium excretion in patients with CKD [24]. In CKD, hypertension is related to RAS activation, sympathetic nervous system activation and nitric oxide inhibition. However, an increase in blood pressure at night is related to a decrease in sodium excretion and hypervolemia [25].

As seen in Table 4, mean NTSBP was significantly different among SGA groups. All blood pressure parameters increased with worsened nutrition, but the only significant difference was detected in nighttime blood pressure measurements. Figure 1 shows that non-dipper increased along with malnutrition, although these differences were not significantly different In a study of 148 hemodialysis patients, similar results were obtained. As malnutrition scores increased, non-dipper and reverse dipper blood pressure patterns increased. Additionally, in that study, there was a positive correlation between malnutrition and systolic blood pressure and mean blood pressure at night [26].

The first study that explored dietary protein-energy intake in patients with excess fluid volume was done in PD patients. In 266 patients, factors related to malnutrition from dialysis were tested. In this cross-sectional study, malnutrition developed as aresult of volume excess and inflammation [27]. Demirci et al., assessed volume using bioimpedance analysis in 95 PD patients and found that hypervolemia was associated with malnutrition-inflammation-atherosclerosis [28]. In another study in which 76 PD patients were evaluated with bioimpedance analysis, patients were grouped in three categories based on the Bilbrey nutrition index as follows:

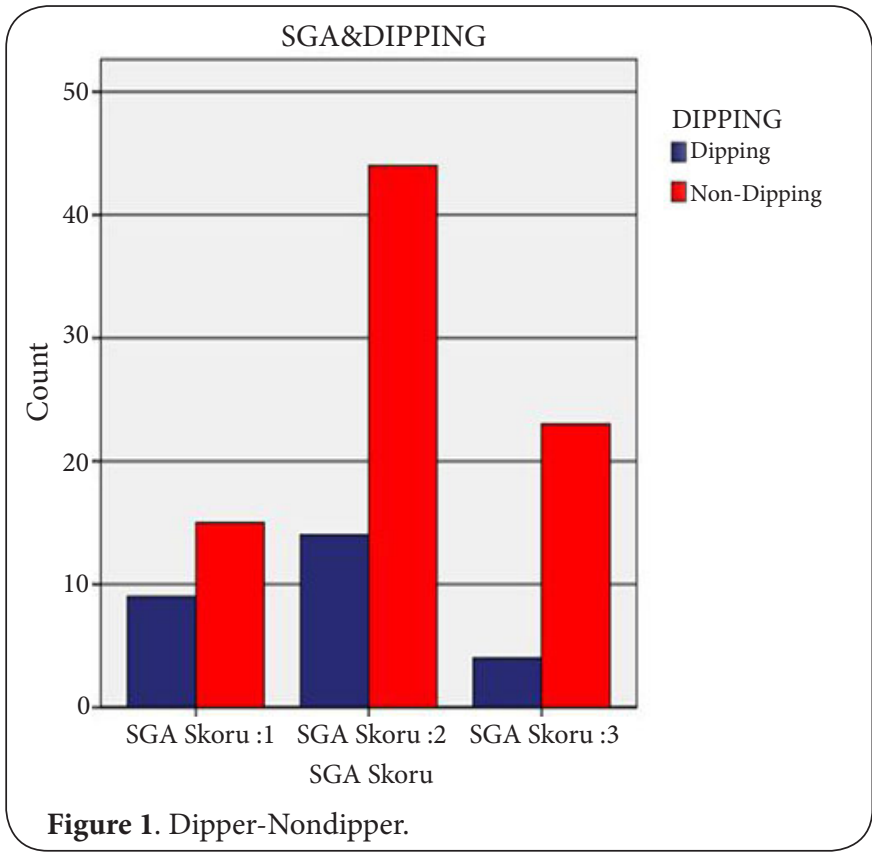

mild, moderate and average malnutrition. It was found that excess volume increased as malnutrition advanced [29]. In 28 PD patients, volume was strongly related to nutrition. It was reported that nutrition improves if excess extracellular fluid is treated and in patients who has disturbance on nutrition develop malnutrition [30].

Kursat et al., showed that nutritional disturbances were related to hypervolemia-related echocardiographic disturbances [31]. In another study, the same group evaluated the level of malnutrition in patients, using the subjective global assessment score, and depression and volume status, using echocardiographic parameters. They found positive correlations among malnutrition, depression and excess volume [32]. A loss of appetite and insufficient nutrition in patients with hypervolemia might be related to increased TNF- $\alpha$ and proinflammatory cytokines [33,34]. An association between increased TNF-a levels with anorexia and malnutrition was shown in PD and chronic heart failure patients. Anker et al., found that increased levels of IL- 6 and TNF- $a$ are related to muscle loss in patients with chronic heart failure [35].

The AASK (African American Study of Kidney Disease) showed that target organ damage was more severe in patients who have high blood pressure at night but are normotensive according to office measurements [36]. In the current study, we observed that an expected decrease in blood pressure at night did not occur in some of the patients who had normal blood pressure. Therefore, we take the ratio of night and daytime measurements and explored the association of this ratio with the parameters of malnutrition (Table 5). NTSBP/DTSBP ratio was significantly different among the groups. In MannWhitney $U$ test SGA-A and SGA-B and SGA-B and SGA-C groups did not differ significantly. However, we found a significant 
difference between SGA-A and SGA-C groups (p:0.024). Moreover, we detected weak and negative correlations between night/daytime blood pressure ratios and BMI, MAC, MAMC measurements, albumin, hemoglobin, cholesterol and triglyceride levels, but these correlations were not statistically significant (Table 6).

If we summarize our results, we found that 24HSBP, DTSBP and NTSBP were inversely and significantly correlated with albumin, essential amino acids, non-essential amino acids and BCCA measures. NTSBP was positively and significantly related to SGA scores. When we tested the relationship between SGA and ABPM parameters in the whole group, we found a significant association between SGA and NTMAP. The association between nighttime blood pressure measurements and nutritional status was thought to be related to excess volume. However, it is not possible to conclude a causal association between hypervolemia and malnutrition, as this was a cross sectional study, and we used only ABP measures as volume parameters. Nevertheless, it should be noted that this is the first study evaluating the possible associations between malnutrition and ambulatory blood pressure and showing significant associations of amino acid levels with blood pressure parameters in predialytic patients.

\section{Conclusion}

Prospective, controlled studies using larger sample sizes are needed in order to explore a causal association between $A B P$ parameters and levels of malnutrition.

\section{Competing interests}

The authors declare that they have no competing interests.

Authors' contributions

\begin{tabular}{|l|c|c|c|c|c|}
\hline Authors' contributions & AI & SK & DAK & CU & VZ \\
\hline Research concept and design & $\checkmark$ & $\checkmark$ & -- & -- & -- \\
\hline Collection and/or assembly of data & $\checkmark$ & -- & $\checkmark$ & $\checkmark$ & $\checkmark$ \\
\hline Data analysis and interpretation & $\checkmark$ & $\checkmark$ & -- & -- & -- \\
\hline Writing the article & $\checkmark$ & -- & -- & -- & -- \\
\hline Critical revision of the article & -- & $\checkmark$ & -- & -- & -- \\
\hline Final approval of article & $\checkmark$ & $\checkmark$ & -- & -- & -- \\
\hline Statistical analysis & $\checkmark$ & -- & -- & -- & -- \\
\hline
\end{tabular}

\section{Publication history}

EIC: Kevin R. Loughlin, Harvard Medical School, USA.

Received: 27-Oct-2014 Final Revised: 13-Nov-2014

Accepted: 29-Dec-2014 Published: 07-Jan-2015

\section{References}

1. Marckmann P. Nutritional status of patients on hemodialysis and peritoneal dialysis. Clin Nephrol. 1988; 29:75-8. I PubMed

2. Bergstrom $\mathrm{J}$ and Lindholm B. Nutrition and adequacy of dialysis. How do hemodialysis and CAPD compare? Kidney Int Suppl. 1993; 40:S39-50. | PubMed

3. Steiber AL, Kalantar-Zadeh K, Secker D, McCarthy M, Sehgal A and McCann L. Subjective Global Assessment in chronic kidney disease: a review. J Ren Nutr. 2004; 14:191-200. | Article | PubMed

4. Cooper BA, Bartlett LH, Aslani A, Allen BJ, Ibels LS and Pollock CA. Validity of subjective global assessment as a nutritional marker in end-stage renal disease. Am J Kidney Dis. 2002; 40:126-32. | Article I PubMed

5. Stenvinkel P, Barany P, Chung SH, Lindholm B and Heimburger O. A comparative analysis of nutritional parameters as predictors of outcome in male and female ESRD patients. Nephrol Dial Transplant. 2002; 17:1266-74. | Article | PubMed

6. Detsky AS, McLaughlin JR, Baker JP, Johnston N, Whittaker S, Mendelson RA and Jeejeebhoy KN. What is subjective global assessment of nutritional status? JPEN J Parenter Enteral Nutr. 1987; 11:8-13. | Article I PubMed

7. Dervisoglu E, Eraldemir C, Kalender B, Kir HM and Caglayan C. Adipocytokines leptin and adiponectin, and measures of malnutritioninflammation in chronic renal failure: is there a relationship? J Ren Nutr. 2008; 18:332-7. | Article | PubMed

8. Hrnciarikova D, Hyspler R, Vyroubal P, Klemera P, Hronek M and Zadak Z. Serum lipids and neopterin in urine as new biomarkers of malnutrition and inflammation in the elderly. Nutrition. 2009; 25:303-8. | Article | PubMed

9. Salem M. Hypertension in the hemodialysis population? High time for answers. Am J Kidney Dis. 1999; 33:592-4. I Article I PubMed

10. Wilson J, Shah T and Nissenson AR. Role of sodium and volume in the pathogenesis of hypertension in hemodialysis. Semin Dial. 2004; 17:260-4. | Article | PubMed

11. Verdecchia P, Schillaci G, Guerrieri M, Gatteschi C, Benemio G, Boldrini F and Porcellati $C$. Circadian blood pressure changes and left ventricular hypertrophy in essential hypertension. Circulation. 1990; 81:528-36. I Article I PubMed

12. Amar J, Vernier I, Rossignol E, Bongard V, Arnaud C, Conte JJ, Salvador M and Chamontin B. Nocturnal blood pressure and 24-hour pulse pressure are potent indicators of mortality in hemodialysis patients. Kidney Int. 2000; 57:2485-91. | Article | PubMed

13. Klein $\mathrm{S}$. The myth of serum albumin as a measure of nutritional status. Gastroenterology. 1990; 99:1845-6. I PubMed

14. Bergstrom J, Furst P, Noree LO and Vinnars E. Intracellular free amino acid concentration in human muscle tissue. J Appl Physiol. 1974; 36:6937. | Article | PubMed

15. Alvestrand A, Bergstrom J, Furst P, Germanis G and Widstam U. Effect of essential amino acid supplementation on muscle and plasma free amino acids in chronic uremia. Kidney Int. 1978; 14:323-9. | Article | PubMed

16. Whaley-Connell AT, Sowers JR, Stevens LA, McFarlane SI, Shlipak MG, Norris KC, Chen SC, Qiu Y, Wang C, Li S, Vassalotti JA and Collins AJ. CKD in the United States: Kidney Early Evaluation Program (KEEP) and National Health and Nutrition Examination Survey (NHANES) 1999-2004. Am J Kidney Dis. 2008; 51:S13-20. | Article | PubMed

17. Minutolo R, Agarwal R, Borrelli S, Chiodini P, Bellizzi V, Nappi F, Cianciaruso B, Zamboli P, Conte G, Gabbai FB and De Nicola L. Prognostic role of ambulatory blood pressure measurement in patients with nondialysis chronic kidney disease. Arch Intern Med. 2011; 171:1090-8. | Article | PubMed

18. Agarwal R and Andersen MJ. Prognostic importance of ambulatory blood pressure recordings in patients with chronic kidney disease. Kidney Int. 2006; 69:1175-80. I Article I PubMed

19. Lurbe E, Redon J, Kesani A, Pascual JM, Tacons J, Alvarez V and Batlle D. Increase in nocturnal blood pressure and progression to microalbuminuria in type 1 diabetes. N Engl J Med. 2002; 347:797-805. | Article | PubMed

20. Timio M, Venanzi S, Lolli S, Lippi G, Verdura C, Monarca C and Guerrini E. "Non-dipper" hypertensive patients and progressive renal insufficiency: a 3-year longitudinal study. Clin Nephrol. 1995; 43:382-7. | PubMed

21. Palmas W, Pickering T, Teresi J, Schwartz JE, Eguchi K, Field L, Weinstock RS and Shea S. Nocturnal blood pressure elevation predicts progression of albuminuria in elderly people with type $\mathbf{2}$ diabetes. J Clin Hypertens (Greenwich). 2008; 10:12-20. | Article | PubMed

22. Farmer CK, Goldsmith DJ, Cox J, Dallyn P, Kingswood JC and Sharpstone P. An investigation of the effect of advancing uraemia, renal replacement therapy and renal transplantation on blood pressure diurnal variability. Nephrol Dial Transplant. 1997; 12:2301-7. | Article | PubMed 
Inci et al. Clinical Nephrology and Urology Science 2015,

http://www.hoajonline.com/journals/pdf/2054-7161-2-1.pdf

23. Fukuda M, Munemura M, Usami T, Nakao N, Takeuchi O, Kamiya Y, Yoshida A and Kimura G. Nocturnal blood pressure is elevated with natriuresis and proteinuria as renal function deteriorates in nephropathy. Kidney Int. 2004; 65:621-5. | Article I PubMed

24. Bankir L, Bochud M, Maillard M, Bovet P, Gabriel A and Burnier M. Nighttime blood pressure and nocturnal dipping are associated with daytime urinary sodium excretion in African subjects. Hypertension. 2008; 51:891-8. | Article | PubMed

25. Andersen MJ and Agarwal R. Etiology and management of hypertension in chronic kidney disease. Med Clin North Am. 2005; 89:525-47. I Article I PubMed

26. Tekce H, Kursat S, Bahadir Colak H and Aktas G. Effects of nutritional parameters on nocturnal blood pressure in patients undergoing hemodialysis. Ren Fail. 2013; 35:946-50. I Article I PubMed

27. Wang AY, Sanderson J, Sea MM, Wang M, Lam CW, Li PK, Lui SF and Woo J. Important factors other than dialysis adequacy associated with inadequate dietary protein and energy intakes in patients receiving maintenance peritoneal dialysis. Am J Clin Nutr. 2003; 77:834-41. I PubMed

28. Demirci MS, Demirci C, Ozdogan O, Kircelli F, Akcicek F, Basci A, Ok $E$ and Ozkahya M. Relations between malnutrition-inflammationatherosclerosis and volume status. The usefulness of bioimpedance analysis in peritoneal dialysis patients. Nephrol Dial Transplant. 2011; 26:1708-16. | Article | PubMed

29. Espinosa Cuevas MA, Navarrete Rodriguez G, Villeda Martinez ME, Atilano Carsi X, Miranda Alatriste P, Tostado Gutierrez T and CorreaRotter R. Body fluid volume and nutritional status in hemodialysis: vector bioelectric impedance analysis. Clin Nephrol. 2010; 73:300-8. | Article | PubMed

30. Cheng LT, Tang W and Wang T. Strong association between volüme status and nutritional status in peritoneal dialysis patients. Am J Kidney Dis. 2005; 45:891-902.

31. Kursat S, Tekce H, Ekmekci C, Colak HB and Alici T. Relationship between the degree of malnutrition and echocardiographic parameters in hemodialysis patients. Nephron Clin Pract. 2007; 106:c136-42. | Article I PubMed

32. Kursat S, Colak HB, Toraman A, Ekmekci C, Tekce H and Alici T. The relationship between depression-malnutrition and echocardiographicblood pressure parameters in chronic hemodialysis patients. Int Urol Nephrol. 2008; 40:793-9. | Article I PubMed

33. Sonti G, Ilyin SE and Plata-Salaman CR. Anorexia induced by cytokine interactions at pathophysiological concentrations. Am J Physiol. 1996; 270:R1394-402. | Article | PubMed

34. Aguilera A, Codoceo R, Selgas R, Garcia P, Picornell M, Diaz C, Sanchez $\mathrm{C}$ and Bajo MA. Anorexigen (TNF-alpha, cholecystokinin) and orexigen (neuropeptide Y) plasma levels in peritoneal dialysis (PD) patients: their relationship with nutritional parameters. Nephrol Dial Transplant. 1998; 13:1476-83. | Article | PubMed

35. Anker SD, Chua TP, Ponikowski P, Harrington D, Swan JW, Kox WJ, PooleWilson PA and Coats AJ. Hormonal changes and catabolic/anabolic imbalance in chronic heart failure and their importance for cardiac cachexia. Circulation. 1997; 96:526-34. I Article I PubMed

36. Pogue V, Rahman M, Lipkowitz M, Toto R, Miller E, Faulkner M, Rostand S, Hiremath L, Sika M, Kendrick C, Hu B, Greene T, Appel L and Phillips RA. Disparate estimates of hypertension control from ambulatory and clinic blood pressure measurements in hypertensive kidney disease. Hypertension. 2009; 53:20-7. | Article | PubMed

\section{Citation:}

Inci A, Kursat S, Kutsal DA, Ulman C and Yavuz V. Hypervolemia-malnutrition in renal failure: Is there a relationship? Clin Nephrol Urol Sci. 2015; 2:1. http://dx.doi.org/10.7243/2054-7161-2-1 